\title{
Classification of Some Fruits using Image Processing and Machine Learning
}

\author{
Dilara Gerdan Koç ${ }^{1, a, *}$, Mustafa Vatandaş ${ }^{1, b}$ \\ ${ }^{1}$ Department of Agricultural Machinery and Technologies Engineering, Faculty of Agriculture, Ankara University, 06110 Ankara, Turkey \\ *Corresponding author

A R T I C L E IN F O A B S T R A C T

Research Article \\ In this study, an image processing algorithm and classification unit were developed to classify the \\ fruits according to their size and color characteristics. For this purpose, a total of 300 fruits (50 fruit \\ samples from each of the Starkrimson Delicious and Golden Delicious apple varieties, Washington \\ Navel and Valencia Midknight orange varieties, Ekmek and Eşme quince varieties) were used in \\ Received : $13 / 05 / 2021$ \\ Accepted : 26/11/2021 \\ the experiments. The size and color values measured with a caliper and a spectrophotometer were \\ entered in the developed image processing algorithm to determine the success rates of classifying \\ the fruits. The integration of image processing algorithm with the classification unit classified $88 \%$, \\ $100 \%, 96 \%, 82 \%, 86 \%$, respectively. On the other hand, the size and color values read in fruits with \\ the image processing algorithm were evaluated using predictive techniques used in data mining. \\ For this purpose, K Nearest Neighbor (KNN), Decision Tree (DT), Naive Bayes classification and \\ Keywords: \\ Fruit classification \\ Image processing \\ Real-time video processing \\ Multilayer Perceptron Neural Network (MLP) algorithms were used. Algorithms were run with 10- \\ fold cross validation method. In the training of artificial classifiers, the success was $93.6 \%$ for KNN, \\ 90.3\% for DT, $88.3 \%$ for Naive Bayes, $92.6 \%$ for MLP and $94.3 \%$ for RF.
} Machine learning Post-harvest technology

\section{Introduction}

The external features such as color, size, texture, different flaws and shape in the products to be offered to the market are important features in classification and grading. One of the most important quality features in fruits and vegetables is their appearance. The appearance not only affects the market value of the products, its preferences and the choice of the consumer, but it also affects the interior quality to a certain extent. Problems arising from processes such as classification, packaging and storage of fresh fruits and vegetables before they are placed on the market determine the market price formation and consequently affect the producer income (Pezikoğlu et al 2004). Manual quality control of the fruit takes time and labor intensive. Therefore, computerized vision systems are widely used for automation-based external quality control of food and agricultural products. Today, with advances in machine vision can produce accurate, fast, objective and efficient results in the non-destructive fruit classification due to the availability of low-cost hardware and software (Naik and Patel 2017).
According to the report of the Fresh Fruit and Vegetable Workshop published by the General Directorate of Agricultural Research and Policies in 2019, there was an increase of $24.03 \%$ in total fruit yield, $21.03 \%$ in the production area and $50.11 \%$ in the production amount. However, this increase causes approximately $30-40 \%$ of product to be wasted in total production due to wrong mechanization applications after harvest. Applications of post-harvest technologies can minimize the loss of fresh fruits and vegetables from harvest to consumption, reduce quantitative and qualitative losses, as well as maintain product quality, such as nutritional value, physical appearance and sensory properties. Some studies show that there are large differences between post-harvest losses of developing and developed countries, with estimated losses between $2 \%$ and $23 \%$ (Singh et al 2014). Studies on image processing have continued from past to present. For example; some of the researcher were used image processing techniques for edge detection, feature extraction and color detection of yellow, red and green apples in their study on yield mapping in peach fruit, using 
image processing techniques such as histogram thresholding and logarithm transformation, color, texture and shape of images taken under natural conditions. Feature extraction method has been used and algorithms have been developed. In the event that a fruit comes in front of the camera, the system processes the image taken from the camera and provides numerical and visual information about the size and color of the fruit examined on the screen (Tonguç 2007; Kim et al 2009; Kurtulmuş et al 2014). The researcher stated that some of the algorithms he developed have been successful in determining the fruit at the level of $85 \%$. Sungur and Özkan (2015) made a quality control application using MATLAB software to detect pollution in chicken eggs and calculate egg volume. The researcher used the fuzzy logic algorithm to determine the degree of quality. According to the results obtained, the algorithm developed works with 98\% accuracy. Örnek (2014) investigated the grading efficiency of the real-time image processing system developed with transverse and longitudinal roller-type mechanical carrot sorting machines. The classification of carrots on a belt, which can speed adjusted by a geared motor with classification machine is based on the analysis of these images. According to the results obtained, the ratio of carrots falling to the faulty section in a transverse roll, a longitudinal roll and real time classification machine was found to be between $0.65 \%-99.33 \%, 18.39 \%-88.90 \%$ and 5.42\% - 9.03. Al-Shekaili et al (2016) classified the types of dates grown in various regions of Saudi Arabia according to their hardness. Instead of the traditional expensive and time-consuming methods used to determine the quality of dried fruits, they used artificial neural network and linear discrimination analysis methods by removing histogram and texture features from 1800 images, for example, in the computer vision system they developed. Researchers classified dried fruits into soft, semi-hard and hard. The results were successful for LDA and $84 \%$ for ANN and $77 \%$ for ANN. Jhawar (2016) classified taken from 160 orange photographs using the pattern recognition method. Designed classification system; data collection and processing, feature extraction and making decisions. Images were taken at a resolution of $640 \times 480$ pixels with a digital camera from a special box illuminated with 430 luxurious lights. According to the results of the study, $90 \%$ and $98 \%$ success was achieved in the classification of oranges. Ishikawa et al (2018), in their study, classified the strawberries by using the shape information taken from digital images. Using the SHAPE software, they used fruit length, width, projection area and fruit border lines data from 2969 photos for classification. They emphasized that the method of machine learning was successful in identifying strawberry fruits of nine different shapes. Li et al (2019) have developed an online optical and spectroscopic-based system for the rapid determination of internal and external quality in apples after harvest. A new image segmentation method has been developed in order to determine the image of apple containing all surface information in the online detection system consisting of the external quality detection mechanism and the internal quality detection mechanism. In the study, the fruit external quality assessment rate was $96.76 \%$, the correlation coefficient in size measurement was 0.9763 , and the root-mean-square error (RMS error) was $1.3243 \mathrm{~mm}$.

In this study, apple, quince and orange fruit varieties were tried to be classified according to the color and size by developing an image processing algorithm.

\section{Materials and Methods}

\section{Biological Materials}

In this study, apple, orange and quince varieties were used as biological materials. In studies on the classification of fruits using image processing techniques, the number of sample sizes taken varies between 43 and 948 (Örnek 2014; Yabanova and Yumurtac1 2018). Besides these values, considering the statistical evaluation principles, the sample number for each variety was determined as 50 fruits.

\section{Software and Measuring Devices}

LabVIEW (Laboratory Virtual Instrument Engineering Workbench) package program was used to develop image process algorithm. And digital caliper was used to measure fruit diameter values. The digital caliper is capable of reading with a sensitivity of $1 / 100 \mathrm{~mm}$. Xrite Ci60 model portable spectrophotometer was used to obtain color data from fruits. The spectrophotometer is able to determine the color values in the wavelength range of $400-700 \mathrm{~nm}$ in more than one color space and in this study, the desired $L^{*}$ $a^{*} b^{*}$ color space measurements was made. (Figure 1a).

\section{Classification Unit}

In the study, Logitech C930E model web cam was used to obtain images of fruits (Figure 1b). The dimensions of the camera are $29 \times 94 \times 24 \mathrm{~mm}$ and can take up to $1920 \times$ 1080 pixels. The camera used is placed on a tripod so that the classification device can be seen from the top.

The belt conveyor, which is the most important component of the classification unit, was manufactured from stainless steel chrome sheet and aluminum material. The conveyor belt has a tape of $88 \mathrm{~mm}$ width, $2 \mathrm{~mm}$ thickness, $650-700 \mathrm{~mm}$ and is black and can eliminate the electrostatic effect. All of the fasteners of the belt conveyor are made of stainless material. The outer diameter of the drive roller is $32 \mathrm{~mm}$, but there are holes of $25 \mathrm{~mm}$ depth and $8 \mathrm{~mm}$ diameter on both ends of the roller. One end of the drive roller is $14 \mathrm{~mm}$, the other end is $17 \mathrm{~mm}$ in diameter and it is made of aluminum to prevent the bearings from rusting (Figure 1c).

The spindle conveyor drive roller of the DC motor operating the belt conveyor is coupled by direct engagement. The output speed of the DC motor reducer is $90 \mathrm{~min}^{-1}$ and the motor operates with a nominal $24 \mathrm{~V}$ DC voltage. The speed of the band can be adjusted with a DC motor driver added to the system. The motor driver added to the system can control the motors in the range of 5 - 30 volts.

In the classification device, two pneumatic doubleacting cylinders, which perform the main separation, are used. NPN type transistors were used to trigger the pistons. It is energized by means of $24 \mathrm{~V}$ with a capacity of 0,15 $0,8 \mathrm{MPa}$ as directional control valve. A pair of solenoid valves that control the pistons and a compressor with a maximum capacity of 6.8 bar producing the required compressed air has been added to the system. 


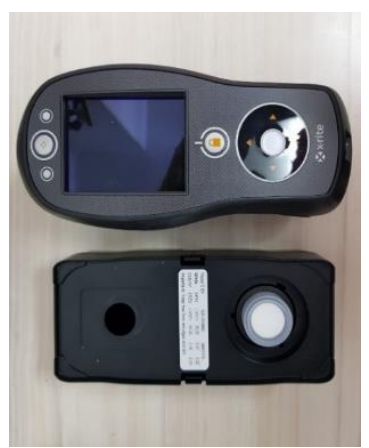

(a)

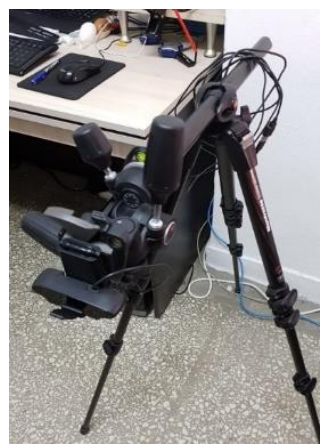

(b)

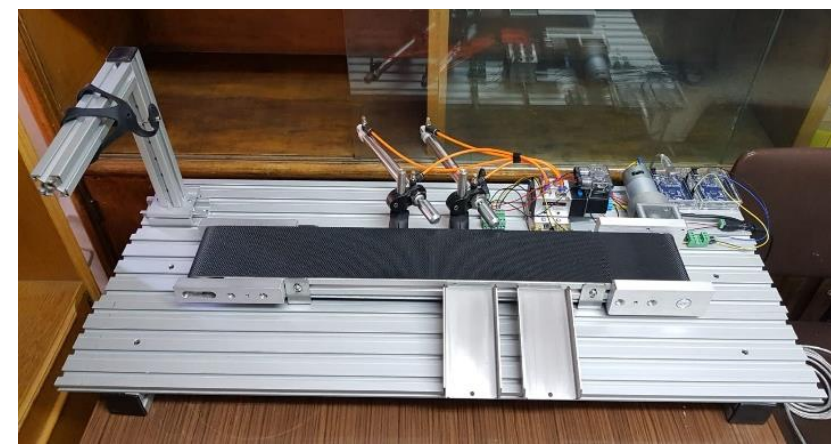

(c)

Figure 1. Spectrometer and calibration plates (a), camera and tripod unit (b), Belt conveyor system(c)

Arduino development board was used to control the pneumatic pistons on the belt system. Arduino Uno is a development board that uses Microcontroller (ATmega328), which contains 14 digital input-output pins and 6 analog input pins that can be connected with various boards and other circuits.

\section{Method}

In the first stage of the measurements, the randomly selected apple, quince and orange varieties were numbered with labels affixed to the stem pit, and then the maximum distance between the flower pit and the stem pit of the fruits was measured and recorded. A total of 300 measurements were obtained. In the measurements carried out by the algorithm, the size readings were determined by first converting the RGB images taken from the fruits to the grayscale images and then determining the borders (edge detection). A platform placed under the fruits allows the widest parts to be measured by the camera. Under the camera, the fruit is placed so that the flower pit is below. The measurements were made according to the classification values specified in TSE standards. In Table 1 , the minimum diameter values determined by TSI for apple, in Table 2. the length characteristics of the orange determined by TSE are also given. The algorithm developed for the apples is coarse and normal size, and for the oranges, the size number is between $0 \ldots 13$, which is indicated on the front panel in the height indicators and classified by opening pistons on the belt.

Xrite Ci60 spectrophotometer color readings on the three surfaces determined from the vicinity of the stalk pit of fruits and the average of three-color channels (L, a, b) were obtained. The imported Lab color values are converted to RGB color space. Delta $\mathrm{E}$ is a measure of color difference and is determined using the Euclidean distance between two samples in the LAB space. Color image quality, the camera that captures images, etc. devices, compression on the image, restoration, rearrangement, image transmission depends on many factors such as (Ouni et al. 2008). For this reason, Delta E value is also given to indicate the color difference between the color values taken by spectrophotometry and image processing. Surfaces with color readings were then placed in a position where the camera could see, and the real-time measurement results of the developed image processing algorithm on the same surface were recorded in the Excel file. The color values are divided into classes only for apples within the standard set by TSE.
The size and color values read with caliper and spectrophotometer were entered into the developed image processing algorithm and the success of classifying the fruits correctly was determined.

\section{Machine Learning Algorithms}

In the readings performed by the algorithm, a database of three hundred objects with four numerical qualities (fruit diameter, $\mathrm{R}$ color channel, $\mathrm{G}$ color channel and B color channel) was created from the size and color values of apple, orange and quince. Class assignments (labels) of fruits whose qualities are determined in the database have been made. Using the KNIME Analytics Platform software, the data were introduced with descriptive statistical methods, and then analyzed with the classification techniques used in data mining. KNN, decision tree, Naive Bayes classification, Random Forest and MLP are used in the classification where tag values are tried to be predicted (Figure 2.). In the decision tree formation, gain information was taken as the basis of quality and minimum description length (MDL) was used as pruning method. Decision Tree algorithm evaluates how well each sample separates its attributes according to target classes by using information gain and entropy. The distinguishing feature with the least entropy is selected and used as a test at the root node of the tree. Entropy is a measure commonly used in information theory that characterizes the homogeneity of samples. The greater the difference of the data, namely the entropy measure, the more uncertain and unstable the results found with that data. If all objects are in the same class, entropy is zero (Silahtaroğlu 2016; Köse 2018). Entropy is calculated with the following equation:

$$
\operatorname{Entropy}(\mathrm{Nj})=\sum_{\mathrm{i}=1}^{\mathrm{c}} \frac{|\mathrm{Ni}|}{|\mathrm{Nj}|} \log _{2} \frac{|\mathrm{Ni}|}{|\mathrm{Nj}|}
$$

Here;

$\mathrm{N}_{\mathrm{j}}$ : Total number of records of $\mathrm{N}$ attributes in the attribute set,

$\mathrm{N}_{\mathrm{i}}$ : Refers to the number of records of the i'th option of the attribute $\mathrm{N}$ (Köse 2018).

The differences that occur according to this feature in order to make the correct classification at the stage of forming nodes and branches according to the distinguishing feature of the samples are called Gain 
Information. Gain Information is obtained by calculating the differences between the weighted sums of the entropies of each subsection (Silahtaroğlu 2016). The Gain Information formula is given below:

$$
\mathrm{D}=\mathrm{H}(\mathrm{D})-\sum_{\mathrm{t}=1}^{\mathrm{n}} \mathrm{P}\left(\mathrm{D}_{\mathrm{i}}\right) \mathrm{H}\left(\mathrm{D}_{\mathrm{i}}\right)
$$

Here;

D: Gain,

H: Entropy,

P: Probability (Weight) (Silahtaroğlu 2016).

Using Bayes theory, it is used to calculate the probability values of the effects of each criterion on the result and to calculate which data is a member of which class (Çalış et al 2013). Naive Bayes classification technique analyzes the condition change situation. For example, in the case where B occurs, the probability of A occurrence is tried to be predicted. At the same time, it can be questioned as the possibility of B occurrence in the case where A occurs (Şeker and Erdoğan 2018).
The training and results processing of this method are very fast, but may be insufficient in solving complex classification problems. Bayes' theorem is calculated by the formula below.

$$
\rho(A / B)=(\rho(B / A) \times \rho(A)) / \rho(B)
$$

In the formula;

$\mathrm{P}$ (A): The predecessor probability of event A,

$P(B)$ : successive probability of event $B$,

P (B | A): Probability of B event when A event occurs,

$\mathrm{P}(\mathrm{A} \mid \mathrm{B})$ : When event B occurs, it is the probability of A event (Çalış et al 2013).

In addition, algorithms were run with 10- fold cross validation method in dividing training and test parts for classification. In this method, it is based on the principle of dividing the dataset into ten parts and using each piece as the test and the remaining nine pieces as the training set. The overall error and success rates of the system are calculated by taking the average of ten results.

Table 1. Smallest diameter measurements accepted by apples according to classes (Anonymous 2007a)

\begin{tabular}{l|ccc}
\hline & Extra & Class I & Class II \\
\hline Large size (L), mm & 65 & 60 & 60 \\
Normal size (N), mm & 60 & 55 & 50 \\
\hline
\end{tabular}

Table 2. Length characteristics of oranges (Anonymous 2007b)

\begin{tabular}{l|ccccccc}
\hline \multicolumn{1}{c|}{ Size No } & 0 & 1 & 2 & 3 & 4 & 5 & 6 \\
\hline Orange $(\mathrm{mm})$ & $92-110$ & $87-100$ & $84-96$ & $81-92$ & $77-88$ & $73-84$ & $70-80$ \\
Size No & 7 & 8 & 9 & 10 & 11 & 12 & 13 \\
Orange $(\mathrm{mm})$ & $67-76$ & $64-73$ & $62-70$ & $60-68$ & $58-66$ & $56-63$ & $53-60$ \\
\hline
\end{tabular}

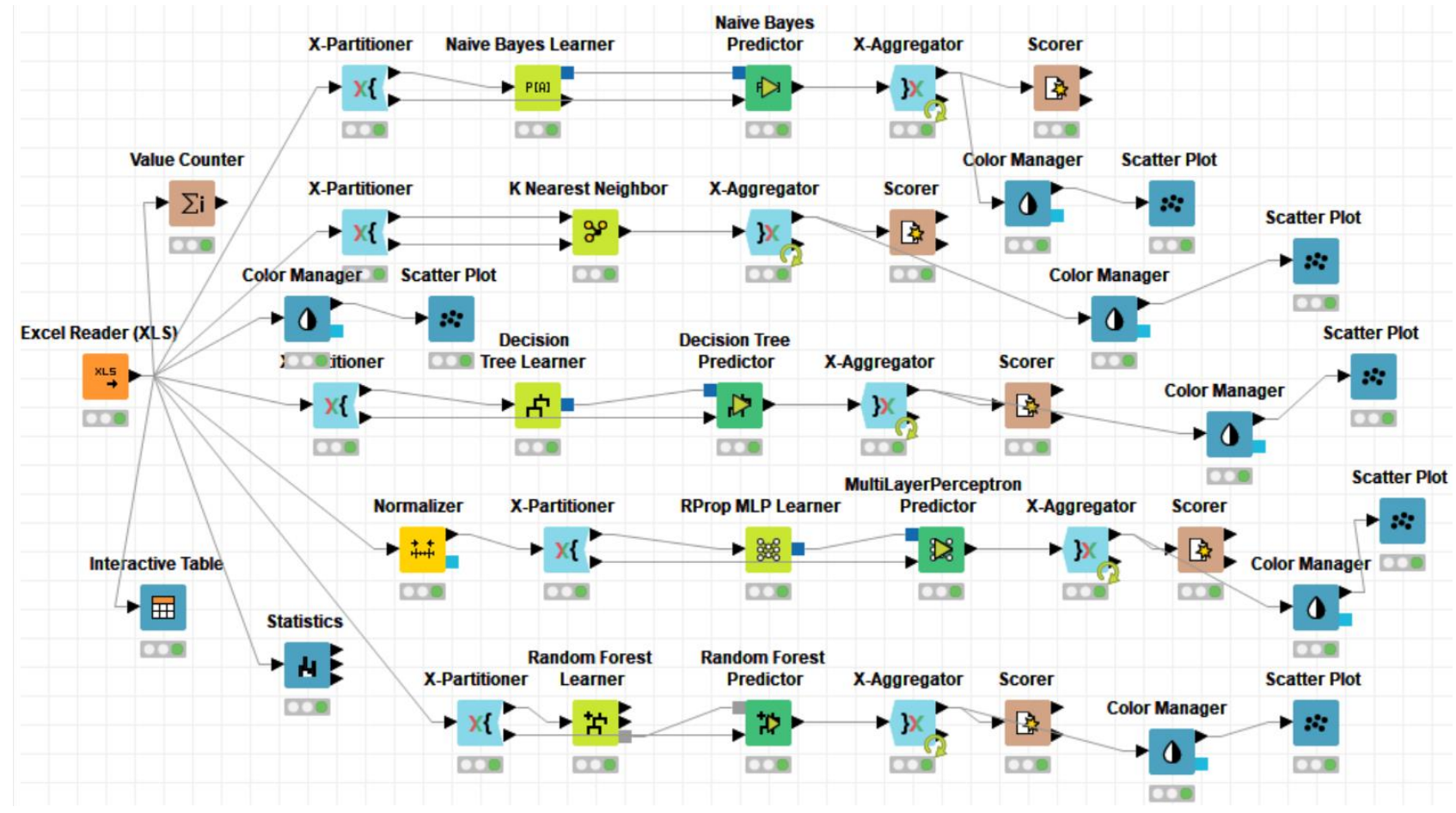

Figure 2. KNIME workflow 


\section{Results and Discussion}

Screen of classification process of the algorithm developed are given in Figure 3. In the attempts made in the classification system for 50 Starkrimson Delicious varieties, 6 wrong classifications were made. In the classification made according to TS 100; for the extra class, the 1st piston was triggered and for the 2nd class apples, the 2 nd piston was triggered. In apples that are in the first class, pistons were not triggered and passed directly over the belt. Its success in the classification in Starkrimson Delicious apple variety was $88 \%$. In 50 Golden Delicious apple varieties, the classification success by dimensions was $100 \%$. Er et al. (2013) studied real-time image processing for classification process of apple varieties using a the belt conveyor. Color, size parameters and fruit weights estimated from size and area values, and the system's success was $95.5 \%$ stated. Bul et al (2005) in their study on the classification of good and bad quality beans using image processing techniques, they achieved $87 \%$ success in real-time processing and classification of beans on the belt driven by two DC motors.

The orange classification process was carried out again according to the class numbers specified by TS 34 . For 0 2 group, the first piston, for 3- 6 group, the 2 nd piston was triggered, in 7-13 group, the pistons were not triggered and free passage was allowed. In orange varieties, there is the possibility of being in more than one group at the same time in terms of fruit diameter. According to TS 34;

Group 0...2: Oranges with a minimum diameter of 84 $\mathrm{mm}$ and a maximum diameter of $110 \mathrm{~mm}$,

Group 3...6: Oranges with a minimum diameter of 70 $\mathrm{mm}$ and a maximum diameter of $92 \mathrm{~mm}$,

Group 7...13: Refers to oranges with a minimum diameter of $53 \mathrm{~mm}$ and a maximum diameter of $76 \mathrm{~mm}$. In the measurements of fruit sizes, if the product diameter was measured with the lower limits, it was evaluated as if it was in the following group. Because the diameter values measured by image processing are due to the tendency to give more values than the caliper (measured) diameter values. When analyzed, classification success by size for Washington Navel variety was $96 \%$ and $82 \%$ for Valencia Midknight variety. In the study of Jhawar (2016), 90\% and $98 \%$ success were achieved in the classification of oranges by using the pattern identification method over the photos taken from 160 oranges.

Considering that there is no classification in terms of size and color in the quince classification process according to TS 1817 . The classification process was made by determining the smallest and largest diameter values for both varieties and entering the lower and upper limit values of the diameter measurements that were read by the caliper in the algorithm. In both quince varieties, the 1 st piston was triggered for correct classification, and the 2nd piston for incorrect classifications. With this method, system success was $95 \%$ with 5 incorrect readings in Ekmek quince variety and $86 \%$ with 7 incorrect readings in Eşme quince variety. When the upper and lower limit values obtained from the spectrophotometer were entered for each color channel, the success of apple varieties in terms of color was found to be $100 \%$. However, orange and quince varieties were unsuccessful in the classification according to color because, there were no significant differences in colors. Delta E values ranged from 5.86 to 37.44 (Table 3.). In Figure 4, regression graphs of fruits are given.

Sabanc1 et al. (2016) Using image processing techniques to classify Golden Delicious, Granny Smith and Starking Delicious apple varieties, the values obtained by using Bayes Net, Naive Bayes, K Star, SMO, RBF Network, RBF Classifier, MLP Classifier, J48, Random Tree and Random Forest algorithms. they achieved a success rate of $95.56 \%$ with the J48 algorithm in their classification and $97.78 \%$ on the MLP Classifier algorithm in color classification. Küçükönder et al. (2015) KStar compared the success of the algorithms by classifying the color data from Random Forest and tomatoes using C4.5 algorithms. As a result of the comparison, they found the accuracy rates of Kstar, Decision Tree (C4.5), and Random Forest algorithms as $100 \%$, $70.74 \%$, and $98.30 \%$, respectively. Al-Shekaili et al. (2016), in the study where they classified the varieties of dates grown in various regions of Saudi Arabia according to their hardness, extracting histogram and tissue properties from the monochrome images of 1800 samples, using artificial neural network (ANN) and linear discrimination analysis (LDA) methods, $84 \%$ for LDA and\% for ANN. They have achieved 77 percent success. Dried fruits were classified as soft, semihard and hard in the study, $84 \%$ for LDA and $77 \%$ for YSA. Ataş (2016) used image processing to extract robust features in his study on Siirt pistachio, and classified the obtained mechanical data with NB, ANN and SVM, which are supervised machine learning algorithms. He stated that the highest classification success was ANN with an accuracy of 83.33\%. Solak and Altınışık (2017) used image processing techniques and average-based classification and K-means clustering methods to identify and classify hazelnut fruits in their studies. While the hazelnut fruit detection was detected with $100 \%$ success by image processing, they achieved a classification success of $90 \%$ and $100 \%$, respectively, with the other algorithms used. White et al. (2017) analyzed the length, width and color data determined by image processing from some olive varieties grown in Spain with ANN. The researchers reported that the diagnosis of fruit sizes with ANN can be made with $90 \%$ accuracy. Yabanova and Yumurtac1 (2018) classified dynamically weighed eggs with support vector machines. In the application, they found $100 \%$ success in training and testing up to 11 input data. Koklu ve Ozkan (2020) studied on multi-class classification of dry beans. For this aim, taken images from dry beans and evaluated machine learning algorithms. MLP, SVM, KNN, DT algorithms scores were 92.36\%, 100.00\%, 95.03\%, $94.36 \%, 94.92 \%, 94.67 \%$, and $86.84 \%$ respectively. Confusion matrix and accuracy criteria for all algorithms are given in Table 4. 


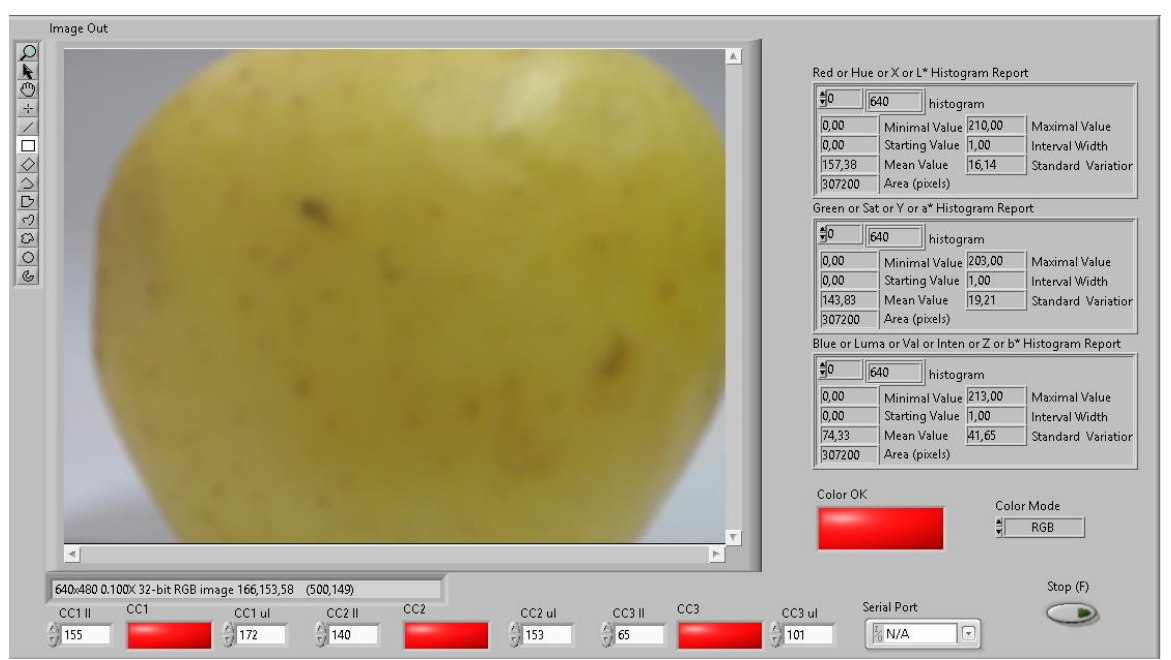

Figure 3. Screen of classification process
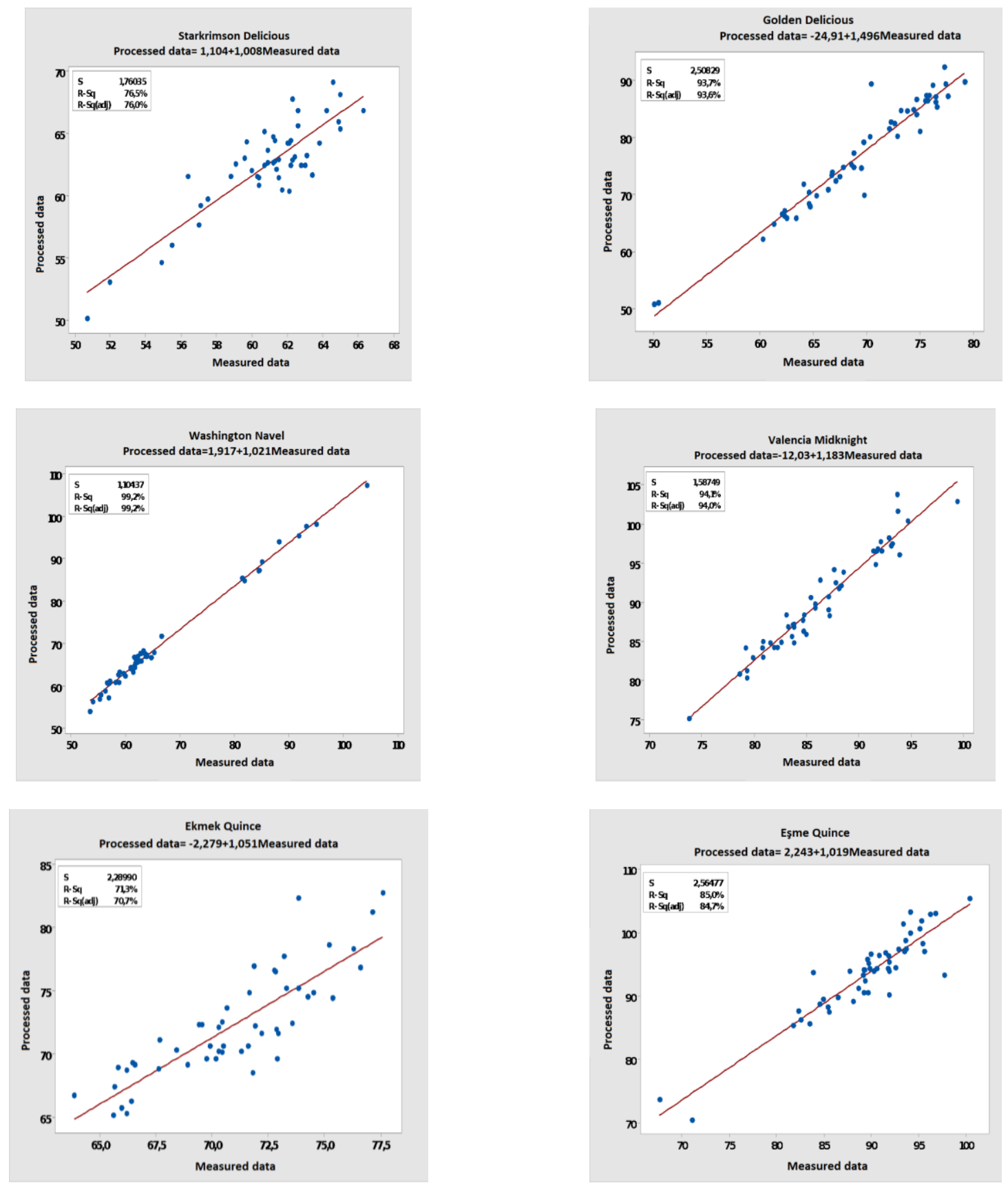

Figure 4. Regression graphs of fruits 
Table 3. Delta E values of fruits

\begin{tabular}{|c|c|c|c|c|c|c|}
\hline Sample no & $\begin{array}{l}\text { Starkrimson } \\
\text { Delicious }\end{array}$ & $\begin{array}{l}\text { Jolden } \\
\text { elicious }\end{array}$ & $\begin{array}{l}\text { Nashington } \\
\text { Javel }\end{array}$ & $\begin{array}{l}\text { alencia } \\
\text { Iidknigh }\end{array}$ & Ekmek Quince & Eşme Quince \\
\hline 1 & 17.47 & 14.92 & 14.93 & 9.59 & 9.56 & 11.58 \\
\hline 2 & 18.78 & 21,93 & 17.43 & 9.18 & 10.21 & 11.5 \\
\hline 3 & 19.88 & 15.26 & 16.85 & 10.39 & 7.36 & 16.06 \\
\hline 4 & 19.59 & 21.67 & 12.81 & 10.79 & 6.41 & 15.02 \\
\hline 5 & 17.73 & 22.62 & 7.05 & 6.53 & 6.08 & 5.83 \\
\hline 6 & 28.41 & 20.96 & 11.57 & 9.77 & 9.97 & 9.48 \\
\hline 7 & 6.14 & 19.04 & 11.71 & 10.5 & 13.01 & 10.27 \\
\hline 8 & 14.55 & 14.97 & 12.65 & 11.85 & 10.66 & 4.58 \\
\hline 9 & 11.9 & 15.11 & 14.02 & 16.31 & 10.38 & 13.27 \\
\hline 10 & 22.1 & 19.19 & 18.59 & 12.28 & 9.17 & 10.05 \\
\hline 11 & 16.72 & 17.38 & 13.18 & 11.89 & 11.81 & 4.91 \\
\hline 12 & 11.06 & 20.14 & 3.18 & 9.03 & 13.4 & 11.54 \\
\hline 13 & 23.59 & 20.97 & 20.28 & 9.3 & 5.17 & 11.08 \\
\hline 14 & 20.59 & 16.47 & 12.67 & 14.08 & 9.24 & 2.61 \\
\hline 15 & 27.89 & 16.24 & 18.05 & 8.9 & 6.03 & 7.37 \\
\hline 16 & 12.86 & 19.75 & 12.85 & 10.44 & 6.63 & 7.85 \\
\hline 17 & 21.29 & 20.16 & 13.4 & 5.54 & 10.89 & 9.16 \\
\hline 18 & 7.09 & 12.02 & 14.35 & 7.88 & 7.06 & 7.35 \\
\hline 19 & 27.41 & 16.74 & 13.36 & 10.66 & 10.39 & 4.1 \\
\hline 20 & 27.28 & 17.98 & 8.84 & 8.17 & 12 & 5.74 \\
\hline 21 & 17.19 & 20.64 & 10.42 & 12.67 & 13.36 & 9.62 \\
\hline 22 & 20.44 & 21.4 & 8.73 & 13.2 & 14.97 & 4.01 \\
\hline 23 & 20.76 & 18.98 & 12.02 & 8.1 & 9.64 & 12.73 \\
\hline 24 & 23.67 & 18.98 & 10.92 & 9.59 & 10.27 & 10.45 \\
\hline 25 & 8.77 & 21.12 & 17.15 & 5.69 & 15.27 & 7 \\
\hline 26 & 23.08 & 17.97 & 10.53 & 7.47 & 14.39 & 11.63 \\
\hline 27 & 20.3 & 18.14 & 12.07 & 7.12 & 11.24 & 5.17 \\
\hline 28 & 23.21 & 18.42 & 16.84 & 8.79 & 14.35 & 7.16 \\
\hline 29 & 16.94 & 15.25 & 12.58 & 12.83 & 15.89 & 9.92 \\
\hline 30 & 22.11 & 21.53 & 12.54 & 7.49 & 14.12 & 12.36 \\
\hline 31 & 16.58 & 20.12 & 12.82 & 10.15 & 7.55 & 9.5 \\
\hline 32 & 23.52 & 22.02 & 15.61 & 12.46 & 14.93 & 10.28 \\
\hline 33 & 26.05 & 16.77 & 10.54 & 8.34 & 16.31 & 8.97 \\
\hline 34 & 33.27 & 20.96 & 9.43 & 13.81 & 14.42 & 11.778 \\
\hline 35 & 18.3 & 21.63 & 21.31 & 13.06 & 8.08 & 9.92 \\
\hline 36 & 23.95 & 20.24 & 9.4 & 6.6 & 14.49 & 6.51 \\
\hline 37 & 25.24 & 22 & 17.15 & 9.46 & 15.9 & 6.86 \\
\hline 38 & 37.44 & 21.71 & 16.72 & 9.3 & 7.09 & 7.57 \\
\hline 39 & 19.01 & 17.94 & 12.03 & 9.01 & 6.35 & 8.58 \\
\hline 40 & 22.59 & 22 & 14.58 & 10.89 & 10.13 & 13.62 \\
\hline 41 & 5.86 & 20.4 & 10.33 & 13.07 & 11.1 & 9.02 \\
\hline 42 & 21.02 & 26.94 & 8.02 & 11.11 & 7.62 & 8.26 \\
\hline 43 & 16.17 & 11.17 & 6.91 & 6.95 & 10.56 & 16.77 \\
\hline 44 & 21.37 & 22.05 & 8.64 & 7.11 & 13.89 & 9.56 \\
\hline 45 & 12.01 & 22.81 & 10.41 & 10.29 & 7.61 & 8.73 \\
\hline 46 & 18.95 & 16.93 & 6.09 & 10.08 & 4.52 & 8.12 \\
\hline 47 & 10.73 & 26.63 & 9.64 & 12.71 & 9.73 & 8.76 \\
\hline 48 & 16.91 & 23.04 & 6.46 & 9.75 & 6.14 & 8.44 \\
\hline 49 & 16.8 & 26.29 & 7.09 & 6.61 & 10.43 & 10.11 \\
\hline 50 & 17.74 & 17.61 & 8.48 & 11.23 & 8.96 & 23.91 \\
\hline & Accuracy (\%) & Error $(\%)$ & F-Measure & Recall & Precision & Sensitivity \\
\hline KNN & 93.667 & 6.333 & 0.826 & 0.905 & 0.905 & 0.76 \\
\hline DT & 90.333 & 9.667 & 0.777 & 0.8 & 0.755 & 0.8 \\
\hline Naive Bayes & 88.333 & 11.667 & 0.752 & 0.94 & 0.627 & 0.94 \\
\hline MLP & 92.667 & 7.333 & 0.817 & 0.76 & 0.884 & 0.76 \\
\hline $\mathrm{RF}$ & 94.333 & 5.667 & 0.848 & 0.84 & 0.857 & 0.84 \\
\hline
\end{tabular}




\section{Conclusion}

In the study, an image processing algorithm was developed to classify fruits according to their size and color characteristics, and it was integrated into a classification unit and used in trials. On the other hand, the size and color values read on fruits by image processing software were evaluated with the estimator techniques used in data mining. Algorithms run with 10 -fold cross validation method yielded highly accurate results. Both online and offline classification methods were successful for the fruits that were tested.

\section{Information}

This study is derived from the master's thesis entitled "Classification of Some Fruits with Image Processing Techniques" (Council of Higher Education: https://tez.yok.gov.tr/UlusalTezMerkezi/tezSorguSonucY eni.jsp) supervised by Prof. Dr. Mustafa Vatandas.

\section{References}

Al-Shekaili NH, Manickavasagan A, Al-Mezeini NK, Rahman MS, Guizani N. 2016. Computer vision technique to classify dates based on hardness. Journal of Agricultural and Marine Sciences Vol. 22 (1): 36-41. Anonymous 2007a. Apple Standard. TS 100. Turkish Standards Institution, Ankara/Turkey.

Anonymous 2007b. Citrus Standard. TS 34. Turkish Standards Institution, Ankara/Turkey.

Anonymous 2007c. Quince Standard. TS 1817. Turkish Standards Institution, Ankara/Turkey.

Ataş M. 2016. Extraction of robust features from Siirt pistachio images for pistachio sorting system. Dicle University Journal of Engineering, 7(1): 93-102.

Bul E, Gelen G, Altun H. 2005. Görüntü İşlemeye Dayalı Tarımsal Ürün Sinıflandırma. 11. Ulusal ElektrikElektronik- Bilgisayar Mühendisliği Kongresi, 22-25 Eylül 2005, Şişli-İstanbul. (In Turkish).

Çalış K, Gazdağı O, Yıldız O. 2013. Automatic Detection of Advertising Email Using Text Mining. International Journal of Informatics Technologies, 6(1): 1-7.

Er O, Cetişli B, Sofu MM, Kayacan C. 2013. Real-Time Automatic Apple Classification. Süleyman Demirel University Journal of Natural and Applied Science, 17(2), 3138, 2013.

Ishikawa T, Hayashi A, Nagamatsu S, Kyutoku Y, Dan I, Wada T, Oku K, Saeki Y, Uto T, Tanabata T, Isobe S, Kochil N. 2018. Classification of Strawberry Fruit Shape by Machine Learning. International Archives of the Photogrammetry, Remote Sensing \& Spatial Information Sciences, 42(2).

Jhawar J. 2016. Orange Sorting by Applying Pattern Recognition on Colour Image. Procedia Computer Science 78 (2016) 691 $-697$.

Kim DG, Burks TF, Qin J, Bulanon DM. 2009. Classification of grapefruit peel diseases using color texture feature analysis. Int J Agric \& Biol Eng, Vol. 2 No.3, 41-50p.

Koklu, Murat; Ozkan, Ilker A. 2020. Multiclass classification of dry beans using computer vision and machine learning techniques. Computers and Electronics in Agriculture, 174(), 105507-. doi: 10.1016/j.compag.2020.105507.

Köse İ. 2018. Veri Madenciliği Teori Uygulama ve Felsefesi.
Papatya Yayıncılık Eğitim, 280 s., İstanbul/Turkey. (In Turkish).

Küçükönder H, Vursavuş KK, Üçkardeş F. 2015. Determining The Effect of Some Mechanical Properties on Color Maturity of Tomato With K-Star, Random Forest and Decision Tree (C4.5) Classification Algorithms. Turkish Journal of Agriculture-Food Science and Technology, 3(5): 300-306, DOI:

Kurtulmuş F, Lee WS, Vardar A. 2014. Immature peach detection in colour images acquired in natural illumination conditions using statistical classifiers and neural network. Precision agriculture, 15(1), 57-79. DOI:https://doi.org/ 10.1007/ s11119-013-9323-8.

Li L, Peng, Y., Li, Y., Liu, Y. 2019. A nondestructive on-line detection system of apple internal and external parameters based on optical technique. An ASABE Meeting Presentation, DOI: https://doi.org/10.13031/aim.201900783.

Naik S, Patel B (2017). Machine vision based fruit classification and grading-a review. International Journal of Computer Applications, 170(9), 22-34.

Örnek, MN. 2014. Havuç Sınıflandırmada Gerçek Zamanlı Görüntü İşleme Makinası Tasarımı ve Bazı Mekanik Sinıflandırma Makinaları ile Boylama Etkinliklerinin Karşılaştırılması. Doktora Tezi, Selçuk Üniversitesi, Fen Bilimleri Enstitüsü, Tarım Makinaları Anabilim Dalı, Konya.

Ouni S, Zagrouba E, Chambah M, Herbin M. 2008. A New Generic Colour Full Reference Metric. ISIVC 2008.

Pezikoglu F, Ergun ME, \& Erkal S. 2004. The situation of modern retailers in fresh fruit and vegetable marketing channel. Journal of Ataturk Central Horticultural Research Institute (Turkey).

Sabancı K, Ünlerşen MF, Dilay Y. 2016. Determination Using Image Processing Techniques the Classification Parameters of Apple Varieties Grown in the Karaman Region. Journal of Agricultural Machinery Science, 12 (2), 133-139.

Şeker ŞE, Erdoğan D. 2018. KNIME İle Uçtan Uca Veri Bilimi. 1. Basım, 440 s., Demet Erdoğan Yayınevi. (In Turkish).

Silahtaroğlu G. 2016. Veri Madenciliği Kavram ve Algoritmaları. 3. Basım, 304 s., Papatya Yayıncılık, İstanbul. (In Turkish).

Singh V, Hedayetullah M, Zaman P, Meher J. 2014. Postharvest technology of fruits and vegetables: An overview. Journal of Postharvest Technology, 2(2), 124-135.

Solak S, Altınışık U. 2017. Detection and classification of hazelnut fruit by using image processing techniques and clustering methods. SAKARYA UNIVERSITY JOURNAL OF SCIENCE, Doi: 10.16984/saufenbilder.303850 22 (1), 56-65.

Sungur C, Özkan H. 2015. A real time quality control application for animal production by image processing. Journal of the Science of Food and Agriculture, 95(14), 2850-2857.

Tonguç G. 2007. Fruit Classification Using Image Process Techniques. M.Sc. Thesis, Süleyman Demirel University Graduate School of Applied and Natural Sciences Machine Education Department, Isparta, Turkey.

Yabanova İ, Yumurtacı M. 2018. Classification of Dynamic Egg Weight Using Support Vector Machine. Journal of the Faculty of Engineering and Architecture of Gazi University 33:2 (2018) 393-402. 